$\xi=-1$

\title{
Marine Shipping Industry Within the System of Global Economic Relations Sustainability
}

\author{
Tatyana Frasyniuk $^{1 *}$, Natalia Primachova ${ }^{1}$ \\ ${ }^{1}$ National University "Odessa Maritime Academy", Odessa, Ukraine. \\ *Corresponding author E-mail:fratan@mail.ru
}

\begin{abstract}
In the current article we study patterns and conditions, under which the role of marine shipping industry within the system of balanced sustainable development of mega economics can be increased. We concentrate attention on the synchronism of emerging problems of differentiation certain economical subsystems and issues of keeping the priorities of development and sustainable positioning. Marine shipping industry holds a special position within international economic relations. Being under the general market relations laws, it predetermines the parameters of supply segment in a limited way. That is why unbalanced cargo traffic and fleet freight capacity cause integral and external losses. Despite system dependence on the international trade pattern, commercial shipping is essential for innovative development of big maritime states' industrial sector.
\end{abstract}

Keywords: Commercial shipping; Effective balance; Maritime trade market; Sustainable growth factors.

\section{Introduction}

The nature of peculiar normalized development law show, that directs the countries towards the optimization of their social and economical conditions, reflects the contradictions of reaching the goals by separate countries in the system of limited access to resources. It is known that temporary scarcity of resources and technologies doesn't provide evenness and consistency of economic growth, even when economic unions are created. That is the reason why changing of the economic growth rates becomes a pattern, both in time and within separate economical segments of international relations.

Hence the attention has to be concentrated not on strengthening, but on weakening such contradictions. Everything mentioned above may be illustrated with practical results from recent history. That is first of all an attempt of breaking the oil market order, set by OPEC and supported by Russia. With the USA striving to change its long term strategy of using this segment of global market, stagnation period has started. It was formed due to other transformation factors as well, with those factors making it more difficult to balance economic growth as per the groups of world economy differentiation [1].

In due course, in order to achieve certain results in consuming normalization China has implemented enormously high rates of the economic growth, and the increasing of its participation in the world trade has helped the economic growth in the other countries as well. But at the same time there appeared some issues regarding normalized economic growth in developed economies segment Differentiation of the approach of the newly emerged economic issues solving has basically predetermined the results of presidential elections in the USA and France. However, the problem of economic growth rates differentiation in certain countries still exists, considering the actual standard of living.

Producing rate growth in developed economies is predetermined by the tasks of keeping the high living standards and export expansion. In the developing economies higher growth rate is based on the need of satisfaction of current needs on a normal level and need of resources export for currency inflow. These peculiarities reflect on the modern trends of formation of maritime trade market.

Intensification of problems of managing sustainable economic growth assumes concentration of the attention on the most important directions of rational economic growth. Herein by rationality of economical growth the authors of the article understand the most effective usage of natural resources and formation of leveling-off process of the living standards in different countries to avoid immigration, that took place in Europe in the second half of 2010s.

\section{Peculiarities of Marine Shipping Industry}

Three groups of factors, that predetermine optimization of the marine shipping industry effectiveness within global economic growth, are defined. First group consists of primary economic goals and strategies of certain states of their unions. The second group of system development differentiation factors is predetermined by those decisions and approaches that are based on the principals of regulation, standardization and limitations. A specific place is held by the factors that reflect technological peculiarities of maritime navigating. One of the Institutional factors of European transportation system's competitive ability is minimization of customs inspection down to $10 \%$ of the cargo flow. 
In some of the researches and in practical activities of shipping companies, the factors, that appear at the borderline between two levels of technologies, were not fully taken into consideration. In some situations the trends of marine trade market self-regulation were ignored and certain programs aimed at accomplish individual priorities were implemented. In different periods it regarded trade fleet of EU, Japan, and China. At the same time, new ways of operation cargo traffic have emerged within the global industry, and they needed new forms of incorporation of managing goods, money and information flows.

Proportion between capital and human assets in marine shipping industry was formed and transforms as time goes according to special rules. That is why the rule is: "Machinery is more efficient than human labour and may take its place only if the ratio of marginal revenue from its usage to its marginal costs is higher, than the same ration using humans."[2] In commercial shipping this proportion reflects on the number of fleet personnel. At the same time a considerable part of ships price depends not on the economies in labour, but on provision of safety and reaching lower energy intensity of ship running.

Actual unity of global maritime trade market limits social economical approaches of separate countries till certain point. Unfortunately, this condition is constantly violated by different institutions in Ukraine. That includes both the laws on the state level and certain institutions actions. It is suffice to mention the standing by of gas carriers in Yuzhny port due to bureaucracy regarding transit ammonia. Fines for untimely clearing for leaving the ports may go up to several million USD.

The form of the Port Act implementation is quite ambivalent. The Act provides for creation of Ukrainian Administration of Sea Ports, an institution to control the capital assets of the ports, technically dis-appropriating the ports. It will be signing the contracts on construction and reconstruction of port infrastructure objects. Ports managing directors will be appointed by the Ministry of Infrastructure upon the recommendation of the Head of Administration. The differentiation of structures, that secure normal navigating conditions increases in one sea water area. Port areas and shipping have to be indifferent to any commercial structures, as any diversity of cargo terminal owners has to assure sustainability of commercial shipping.

Administration efficiency in commercial shipping was demonstrated by the results of an international campaign "Week against flags of convenience" that took place in the ports of South-Eastern Asia some time ago. As a result, seamen got 200,000 USD of wages payable.

Being a specific economical enterprise with a strict system of obligations, a port has to enjoy maximal freedom in the structure of the functional activity when implementing specific functions. Regardless the form of ownership supreme control and administration centres should not make operation more complicated. Unfortunately, adoption the Law of ports and creation of Ukrainian Sea Ports Administration, rather than a separate port, only adds more links to the management system.

\section{Conditions of Maritime Shipping Industry Normalized Functioning}

Structure-factor model of development and normalized development of any maritime shipping enterprise is presented. It includes the conditions of results and resources aggregation according to the nature of the interconnections between demand for transportation services and supply of freight or throughput capacity.

Three basic aims based on development conditions are highlighted - rational usage of natural resources, securing of sustainable economic growth [3] a mechanism of securing social and economical standards. Maritime shipping industry holds a prominent place in this process, as it supports the development of international relations and depends on their current state.
Free arrows show presence and influence of the other subsystems of balanced functioning international economic relations.

Modern trend of economic relations globalization, despite its certain targeting on getting system safety and generally rhythmical development of mega economics, cannot fully solve the issues, and the problems appearing only prove that [4]. That is why consistency of global standards and development criteria with national priorities, that predetermines certain changes in the approaches towards core values. This is shown by certain economic contradictions that have appeared between the USA and the EU. It proves that stable relations are problematic (or even impossible) as external diseconomies have appeared

The boxes of the Fig. 1 reflect the fact that modern development is looking to national macro and mega economical needs. Their certain ambiguity predetermines the risk of optimal usage of capital assets, labour and financial resources by main entrepreneurial structures. Therefore the purposes and principals of economic growth of countries and separate industries are differentiated from time to time.

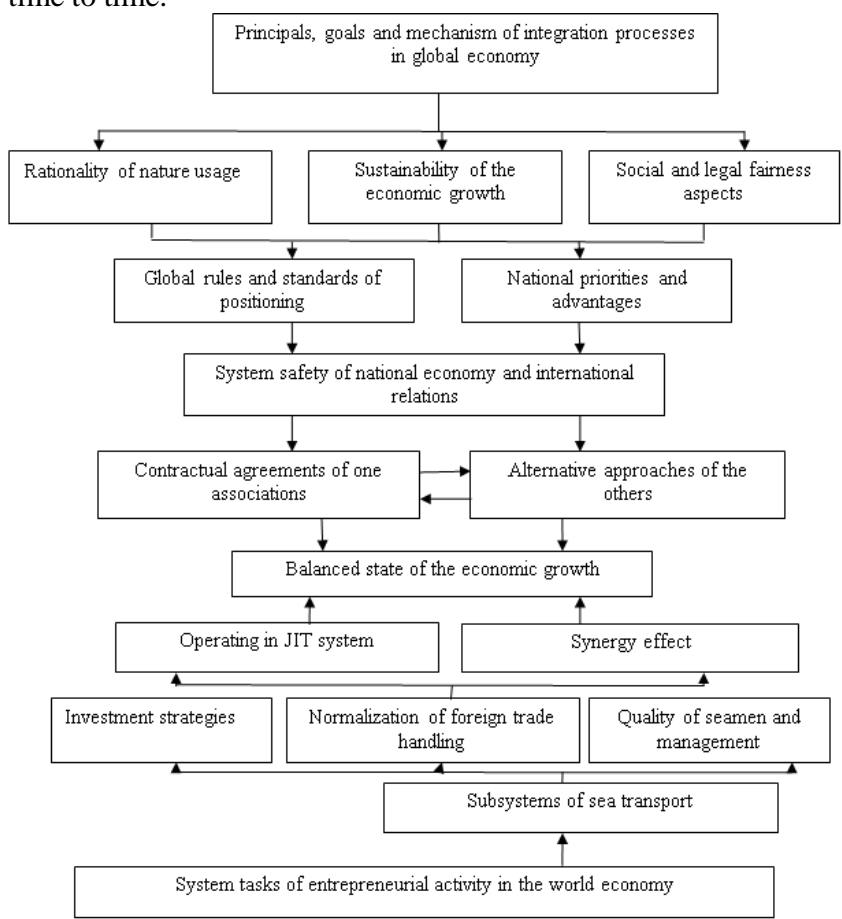

Fig. 1: Information logistics model of balanced development of world economy subsystems

Source: developed by authors

Asymmetrical state may appear in any segment of world economy due to different reasons. In this case we pay attention the kind of reaction one economic communities had on choice and implementation of the strategy by the other ones.

We may recall how the USA, Japan, India and Australia reacted when China attempted to implement "One belt - one road" project, based on efficiency criteria of its transport and economical connections with the EU and Africa. For this very reason there appeared an idea of alternative usage of maritime space, stressing the unity of Indian and Pacific oceans roles.

Asymmetry, that appears from time to time in the economical position of leading economies or their unions, predetermines usage of the sanction principle, as it is always possible to find a reason for them. Sanctions are normally based on limitations, and they may be in the form of political approaches or retreat from WTO rules by implementing special duties.

According to priority positioning principles, commercial ports also get certain advantages depending on their location relative to goods producing and consuming centers. It is also important to have a possibility of cost efficient goods delivery using surface lines of communication. Alongside geographical location transport and cargo flows processing intensity is one of the principal factors in positioning of a port. 
We may use the positions of Ukrainian ports, which are worse comparing to the ones of Novorossiysk and Georgia in the east and Constance in the west. These ports limit significantly transportation services region of Ukrainian ports. Competition rise and a risk of monopolization by the chief operators also have negative impact on the strategy of maximization of market share in maritime trade market.

\section{Optimization of the Subsystems' Roles in the Maritime Transport Industry}

Fleet and ports are still essential, and their importance increases, despite constant differentiation within seaborne trade ${ }^{1}$. Just compare the parameters of economical potentials in the beginning of XXI century. In practice world economy, which exceeds 70 trillion USD (GDP) and world trade (almost 35 trillion USD) are handled by less than 2 trillion USD fleet. The amount of seamen, who provide living of 7 billion people, hardly reaches 1.7 million people.

Regardless the position of the benefits in BCG matrix, we have to consider not only the concentration in the box from supplier's perspective, but the reaction of the consumer as well. That is the reason why there are still plenty of subjects, that break the principle of balance in the market [5].

Unbalanced labour payments for seamen have been a problem for sustainable functioning of the maritime transport market for a long time. Differentiation between the labour rates of the sailors and seamen specialists is noticed. Apart from that, there is an essential difference between the labour payments for the same position on different classes of ships

Keeping every segment of the marine trade market in balance according to the general parameters becomes a problem; the parameters are:

- transportation volumes and fleet freight capacity;

- $\quad$ rates of growth of the chief subsystem resources;

- $\quad$ competition within the priority maritime positions ;

- $\quad$ effectiveness of capital assets and experts work usage;

- $\quad$ social-economical peculiarities and extent of exposure to

regulation technologies of global administrative structures.

Among the criteria of sustainable positioning of enterprising structures [6], special attention has to be paid to:

- market share of technologies, implemented by companies to widen the consumers composition;

presence of potential possibilities to form peculiarities of transportation process by shipping companies;

presence of favourable opportunities for price positioning or sustainable accordance of the prime costs with the labor rates level;

potential opportunity to competitively participate in international shipping.

Outrunning economic growth of the developing economies determines to the certain limit the differentiation of the basic state of OECD countries and certain ecological restrictions violation. At the same time, the differentiation of the economic growth was predetermined by Russia implementing the strategy of avoiding critical import due to sanctions. Partially because of that, the President of the USA considered Russia and China as revisionists, who are solving their own social and economical tasks. Herein China has demonstrated its ability to implement any economic task in the main economical segments of national and global economy. In regard to that, certain attention has to be paid to the priorities of transportation challenges implementation.

\section{Maritime Transport in the System of in- ternational Economic Relations' Safety}

Globalization and integration of economic relations processes within the strategy of sustainable development on one hand pre- condition formation of mega-economical structures, such as World Trade Organization, International Maritime Organization and the others, which form the standards of system safety as well as equation of organized production and its transport servicing. On the other hand, de facto severe competition in achieving strategic dividends within the structure of current state and perspective development still exists ${ }^{3}$. Nevertheless, the parameters of the world economy development reflect relative stability of the growth and balanced state of the global economy's main subsystems [7].

Marine transport serves out over $80 \%$ of the world trade, transporting about 21 billion ton of different cargo. For the surface transport, that co-works with commercial ports, the cargo flow is doubled. That shows the need of strict balance between the terminal capacities of the commercial port and productive potential of the railway stations, adjacent to the port.

Principle of global market subsystems equation of maritime trade when reaching major volumes of cargo shipment, shipbuilding and following utilization of the vessels has formed the problem of commercial ports state optimization and proportional replacement of the old vessels. Appearance of an actually new market segment of marine complex, which is utilization of old vessels, has determined the tasks of equation of ferrous production. Formation of the world centres, where old vessels are utilized, proves high profitableness of this market segment. High labour intensity and ecological danger have also to be considered. That is exactly why the countries of Indian subcontinent became the zone, where this activity is concentrated.

Nature of 2008-2009 crises development has shown, innovative structures, which were developing in strict system of reaction on general economical situation, clearly and in an advance manner reflect hidden inner changes.

As a well-defined economical entrepreneurial organization with a strict system of obligations port has to be maximally free within the structure of functional activity when implementing its specific functions. Despite the form of ownership, top managing and administrative centres must not make the operational activity more difficult. During the Great Depression an Act on shipping and shipbuilding support was passed in the USA. Alongside with the other substandard measures it has assured viability of the country. During the period of industrialization Japan has implemented special regulations of shipbuilding that have raised the industry up to the leading positions in the world. The wave of shipping companies' capital assets concentrated formation and replacement started in the world maritime industry in the period of active global economic growth in 2004-2008. And China's strategy of extensive expansion of commercial fleet should actually be considered as a new phenomenon. Strategies "traditionally maritime nations" stipulated expansion of the freight flow, but China has based its strategy on providing transport independence when participating in the world labour division. Therefore, the fleet, despite its scale, is not among the main regulators of pay balance active state. Reputation and image side of fleet development becomes more crucial.

Comparison of the main trend of transport servicing of international labour division sets for the commercial fleet and country's ports a set of top-priority tasks. The outstanding ones are: normalization of freight capacity of the residents' fleet in reference to the parameters of country's participation in the world trade;

optimization of functional activity of shipbuilding industry within the limits of competitive specialization;

precipitation of logistic links productivity (links specializing in transit cargo flows); accelerated development of local transportation complexes, that provide cooperation with other structural subsystems. De-facto, unified principles of suitability evaluation of its transformation into alternative forms of capital assets ownership were formed in the world transport industry. Objects, that provide system safety and keeping strategic national interests, stay in the 
ownership of the state. Apart from that, the level of population's social security is stressed.

Stimulation of the economic growth in global economy is based on natural laws and specific instrumentarium [8]. Within macroeconomical relations the latter one includes usage of the economical help for developing countries by the developed ones.

\section{Global Factors and Technologies of Anti- Crisis Measures}

The market economy has an aggregate system risks caused by the isolated desire of business structures to the advanced positioning in effective entity's operating segments, excluding similar aspirations of other operators.

Excessive capital inflow in the step of efficient growth of individual sectors, such as maritime transport, forms a high risk to the global, regional and branch economy in the subsequent phases of operation. This is confirmed by the quite high activity of shipbuilding in 2007 - 2008. Imbalance of vessels entry in operation and write-offs of obsolete with respect to the dynamics of foreign trade led to the complication of post-crisis output of merchant shipping in comparison with the parameters of the active pre-crisis order book.

Problematic of choice of a balanced ratio of newbuilding tonnage, the fleet in service and the parameters of economic growth is due to the conservation irrational involving natural resources in production turnover. This applies both to the demand for mineral fertilizers at weather conditions, and deforestation in the equatorial regions. As the main factor of making such decisions are the problems of optimization of currency flows.

In fact, in 2008 - 2013 years there was an unexpected by depth, duration and scope of industries contraction of economic activity. This had a negative impact on freight and as a consequence on the shipbuilding market, whereby the volumes of shipbuilding were significantly reduced at the leading competitive bases of Europe, Japan and South Korea.

It should be noted that the real crisis phenomena cover almost all branches of material production. For example, due to a sharp decline in production of metal the need is reduced for the work of the relevant group of vessels that subsequently adversely affects on the loading of the shipbuilding capacity.

The available shipping supply is calculated in ton-miles by multiplying the available deadweight tonnage of ships by their productivity. By definition, supply must equal demand. If supply is greater than demand, the residual is assumed to be laid up; if supply is less than demand, the fleet productivity must be increased.

From a comparison of the options that affect the structuring of merchant fleet on a standard size it is clear that principle of formation of the carrying capacity of the shipping company on the variety of unit load capacity significantly affects the total amount of the capital cost of the fleet and the number of crew. In these price parameters of operator activity segment depend mainly on overall balance of cargo flows and tonnage, as well as on the structure of goods transported. Last predetermine borders of average load capacity of rated vessel.

Violation of these conditions of equilibrium leads to the differentiation of level of commercial risks for shipping companies. Moreover, the nature and risk parameters are determined by their dependence on specialization and concentration of fleet load capacity.

The external risk factors of financial stability include price formation on products transported by sea in the regions of its consumption. It is important that the price ratios were formed by real factors without affecting speculative technologies in the stock markets.

In addition, it is important to solve two common tasks. On the one hand, the economic and legal cooperation between all participants of the marine trade market, and, on the other hand, management and regulation of individual companies under the terms of the selected operator activity segment. The criteria for positioning is considered the share of mastering of freight flows at the current conditions price formation and timely delivery of various kinds of cargo.

The theory of strategic management involves the necessity in preparing for unexpected changes. Such changes are consistently repeated in the maritime transportation industry. Therefore, the development of emergency anti-crisis measures is important and takes into account the unwanted transformation of freight market. The management of the shipping company should have the skills of action in terms of strategic surprises. The main is the avoidance of situation of financial bankruptcy. The characteristic features of this system should include a number of provisions. In any situation, but especially in the troubled state of the clarity of the important communication network. The main requirement for the subsystem is to ensure the stability of bonds in the complex of measures to resolve crises. The operation of such a network should be based on the collection and processing of incoming information, and the speed of its transmission to the structural units of the company.

Under the same conditions should be reallocated liabilities of company executives. The next ranking prioritize their efforts on solving major problems, you should focus on the composition of capital flows, financial resources and their information systems.

Firstly, the fundamental importance is attached to control and preserve the moral climate in the organization. Secondly, attention is concentrated on the standard operations with minimal disruption. Third, resources management focus on the development and implementation of emergency measures.

To develop and implement appropriate anti-crisis measures operational groups are organized, which, in accordance with the criterion of minimizing the time for decision and implementation of decisions execute the following operations. Because of resources concentrated in the operational groups, a division of strategic actions is formed.

To reduce the time of the management cycle on development and realization of anti-crisis solutions the operational teams and management structures of senior executives should work directly. Senior management forms a new strategy with a specified distribution of responsibilities between the performers. Actually, alternatives of keeping a position in the segment of the operator's activity and the search for ways to reduce costs and preserve the solvency of the shipping company are considered.

\section{Conclusion}

Under the above mentioned conditions all the real maritime states prefer priorities of positioning within the global market of seaborne trade ${ }^{9}$. In Ukraine formation of chain of command as per economic growth criteria has determined civil clerks of transport department stepping up to accordance with sustainability demands. Unfortunately, priorities of macroeconomics and entrepreneurial effectiveness were not considered in this process. Implementation of the chosen strategy was based on political interests that have nothing to do with social and political problems in the country. That is the reason why current managing structures were technically collapsing the whole structure. Fleet is lost on a system level. Ports are loosing their positions as per global parameters.

The model of sustainable and balanced development cannot be based on the priorities of entrepreneurial economy alone. It is also important to consider social factors of society living in the conditions of keeping the effective state of natural subsystems and resources. Differences in developing and functioning of commercial ports in Russia and Ukraine reflect different strategies in appraising the role of maritime transport in the economical safety of international labour division.

In every segment, apart from oligopoly and monopoly ones, the rates levels work as reimbursement of expenses criteria, therefore as technical decision while choosing main parameters of freight 
capacity. Under the conditions of technical-economical level and rates level mismatch it is difficult to manage functional activity.

The level of transportation rates and cargo delivery time influences the nature of current capital formation for enterprises and trade and thus predetermines price fluctuations on consumer goods. From this perspective development of national transportation complex has not only to comply with the commercial tasks of transport owners, but also to be controlled with the perspective of macro-economical interests.

Management system, policy of marine shipping development have to reflect the most important issues, which are to be solved on the governmental level and by entrepreneurial structures - provision of national security and commercial effectiveness. Those predetermine the limits of commercialization and privatization of national transportation complexes in certain countries.

Key peculiarities of shipping complex determine the tasks of integration process, sustainability of transportation services for all the participants of barter transactions. The tasks of normalization of providing people with transport and ecological component of transport enterprises have to be separately mentioned.

\section{References}

[1] Review of Maritime Transport (2017) United Nations, Geneva. ISBN 978-92-1-112922-9, available online: http://unctad.org/en/PublicationsLibrary/rmt2017_en.pdf

[2] Heyne Paul L., Boettke Peter J. \& Prychitko David L. (2005), The Economic Way of Thinking, $11^{\text {th }}$ edn. Upper Saddle River, N.J. Prentice-Hall, pp. 299.

[3] Atkisson Alan (2012), The ISIS Agreement How Sustainability Can Improve Organizational Performance and Transform the World, BINOM, Laboratoriya znanaiy, Moscow, 455 p.

[4] Christensen Clayton M., Anthony Scott D. \& Roth Erik A. (2015), Seeing What's Next: Using the Theories of Innovation to Predict Industry Change, Alpina Publisher, Moscow, $400 \mathrm{p}$

[5] Sachs, Jeffrey D. \& Larrain, Felipe B. (1993), Macroeconomics in the Global Economy, Prentice Hall, 798 p.

[6] Pugel, T.A., Lyndert P.X. (2003), Mezhdunarodnaya ekonomika, Delo i Servis, Moscow, 800 p.

[7] Review of Maritime Transport (2016) United Nations, Geneva SBN 978-92-1-112904-5, available online: http://unctad.org/en/PublicationsLibrary/rmt2016_en.pdf

[8] Griffiths A.; Wall S. (2007) Ekonomika dlya biznesa i menedzhmenta, Balans biznes buks, Dnepropetrovsk, $944 \mathrm{p}$

[9] Handbook of Maritime Economics and Business (2002) It is edited by Prof. Costas Grammenos, City University Cass Business School, London: Lloyd's of London Press, 930 p. 